\title{
Joint Pricing and Inventory Policies for Perishable Items with Price Discount based on
} Freshness Index

\author{
Hardik N. Soni ${ }^{1}$, Kunal Shah ${ }^{2}$ \\ ${ }^{1}$ Chimanbhai Patel Post Graduate Institute of Computer Application, Ahmedabad - 15, India \\ ${ }^{2}$ Research Scholar, Kadi Sarva Vishwavidyalaya, Gandhinagar, India
}

Article History: Received: 10 January 2021; Revised: 12 February 2021; Accepted: 27 March 2021; Published online: 10 May 2021

\begin{abstract}
It is generally observed that the products losses its freshness with the course of time that stimulates depression in demand of the product. In these circumstances, price discounts are necessary to raise the market. This is why, when the product's the index of freshness reaches a certain level, we created an inventory model wherein price reductions are provided at a sale price. The main goal is to figure out what the best selling price and cycle time are in order to maximise profit. The meaning and uniqueness of an ideal model solution are incorporated into the circumstances. The next move is to use a simple algorithm to find an optimal solution. Finally, a numerical example is presented, followed by a sensitivity analysis.
\end{abstract}

Keywords: Inventory, price discount, freshness index.

\section{Introduction}

The term "Perishable products" can be considered for those commodities which lose their value with the course of time, such as fruits, vegetables, flowers, medicines, etc. The freshness of the product and price are the two most substantial elements for customers, hence reducing the prices for less fresh products can be taken into consideration as the most convenient approach to enhance selling of products.

In the literature several models for a peregrinable inventory were suggested. Stock sample tests for deteriorating components have been provided in excellent detail Goyal and Giri (2001), Nahmias (1982), Raafat (1991). Janssen et al. (2016). Bakker et al.(2012) most of the perishable item stock models built follow the random lifetime of items, but their freshness will remain the same and catch the same demand until their expiry date. The concept that freshness of the product effect demand was taken into consideration first by Fujiwara and Parera (1993). Sarker et al. (1997) then considered that the age of stock products had a negative effect on demand. The conduct of consumers regarding the expiry dates for perishable goods was studied by Tsiros and Heilman (2005). Bai and Kendall (2008) studied an inventory model linked with fresh produce where demand is dependent on freshness and displayed inventory. Wang and $\mathrm{Li}$ (2012) developed an inventory model with fixed expiry date for perishable goods in which quality decay is one of the key factor. Zhou and Piramuthu (2013) have developed a declining product inventory model where the demand for each item is based on its instantaneous quality and the allocation of the shelter area. Wu et al. (2016) created a fresh produce stock model in which product freshness, inventory level, and expiration date all influence time-diversity. In 2016, Chen et al. looked into an EOQ for fresh produce, in which demand determines the freshness expiration date and stock levels. Demirage et al. (2017) formulated the inventory ordering problem using a deterministic demand function that is concave in the product age. Dobson et al. (2017) developed an EOQ model based on the assumption that commodity freshness reduces demand rate linearly.

One of the most important factors in deciding whether or not a product will be popular is its price. A variety of studies have looked into the impact of pricing on demand. The inventory models for products that deteriorate because of price-based demand were created Wee (1997), Abad (2003), Mukhopadhyay et al. (2004), Chang et al. (2006), Dye (2007), Hsieh and Dye (2010), Sana (2010, 2011) etc. Maihami and Kamalabadi (2012), Avinadav et al. (2013), Ghoreishi et al. (2014), Farughi et al. (2017), Debata and Acharya (2017) investigated inventory models of non-instantaneous deteriorating items where demand was dependent on price and time.

Qin et al. (2014) present a pricing and batch-sizing strategy for fresh products and foods based on efficiency, selling rates, and visible inventories with ostensible demand. Herbon (2014) created a perishable inventory model in which both freshness and price affect demand. Liu et al. (2015) demonstrated a perishable food inventory model in which demand was determined by the commodity's price and nature. Feng et al. (2017) created and assumed a demand model for inventory management that is focused on price, freshness, and inventory sale. Li and Teng (2018) developed a perishable commodity inventory model in which market price, reference price, product freshness, and the stock level shown all influence demand. A deterministic model for age, stock, and price-based demand goods was submitted by Agi and Soni(2019).

Request price discounts are used to increase profits because fresh products are in higher demand than those with a stale appearance. For perishable goods, Rabbani et al. (2016) established an inventory strategy in which the demand rate is dictated by inventory quality and price fluctuations over time. (Agrawal and Banerjee (2017) presented an inventory model in which demand for a perishable good is initially determined by the purchase price and then by the freshness state, as well as optimum discounting and ordering strategies to optimise net 
profit. Bahula et al (2019) created an ideal inventory model for perishable items with reasearch Article recommending optimal discounting and ordering policies to optimise net profit in the initial selling price and later on freshness, where the conditions for perishable goods were based on optimal discounting and ordering policies to optimise net profit under subsequent price discounts. Kamaruzaman and M. Omar (2020) proposed an EOQ model in which the expiration date, price, and inventory level all influenced demand.

Researchers (Rabbani et al. (2016), Banerjee and Agrawal (2017), Kamaruzaman and M. Omar (2020)) believe the product's freshness tends to deteriorate after a period of storage. Certain items, such as fruits and vegetables, are not suitable because their freshness begins to deteriorate shortly after receiving inventory. This proposed study would then produce a model for inventory in which the freshness of the product degrades as it comes into the inventory and a discount on the sales price will be offered when the product freshness exceeds a certain level. The primary objective is to identify the best sale prices and cycle times to maximise benefit.

The rest of the article is structured in the same way. The notations and assumptions of the model are discussed in section 2. Section 3 shows both the generated mathematical model and the theoretical results. The numerical findings and sensitivity analyses are presented in Section4. Section 6 concludes the paper and recommends prospective research.

\section{Notations and Assumptions}

The mathematical model in this article was built using the notations and assumptions mentioned below .

\subsection{Notations}

$K$

$c$

The fixed order cost per cycle.

The unit purchase price.

$h \quad$ The cost of keeping a unit for a given amount of time.

$\alpha \quad$ Level of freshness index from which discount is offered, $0<\alpha \leq 1$.

$t_{1} \quad$ Time at which the freshness index reaches to $\alpha$.

$p \quad$ Until the discount on the purchase price is given, the selling price per product.

$p_{1} \quad$ After the discount on the sale price is applied, the selling price per unit is calculated.

$D(p, t) \quad$ The commodity demand on time $\mathrm{t}$.

$\beta$

Percentage of discount offered on selling price $\mathrm{p}$.

$\theta \quad$ The inventory deterioration rate.

$n \quad$ Maximum life time.

$I(t) \quad$ The inventory level at time $\mathrm{t}$.

$d(p) \quad$ The price portion of the product's production. It may be non-negative continuous, convex , lower sale price function.

$Q \quad$ The amount of your order.

$T \quad$ The duration of the cycle.

$\pi_{c}(p, T) \quad$ The per cycle profit.

$\pi(p, T) \quad$ The profit per unit of time.

\subsection{Assumptions}

1. The inventory in question suffers from two types of degradation over time: a gradual physical deterioration of the current stock and a deterioration of the freshness of the commodity.

2. Several factors that include high temperatures, humidity, chilling, etc.Can decrease product freshness. A clear index of freshness for a commodity does not seem possible. It is obviously understood nevertheless that, over time, the freshness of every product has constantly degenerated and eventually expires. In consequence, we can deduce that the freshness index begins at 1 , at time 0 , and ultimately decreases to 0. As Chen et al. (2016) did, we infer that the freshness index at times t decreases linearly from 1 at the start of life to 0 at the close of life:

$f(t)=\frac{n-t}{n}, 0 \leq t \leq n$

3. A Discount is available when a product's freshness index falls to a certain level $\alpha(0<\alpha<1)$, i.e.

$$
f(t) \leq \alpha
$$

4. The Demand for the fresh product is definitive. It is both based on the freshness index and the price: 
$D(p, t)= \begin{cases}d(p) f(t) & \text { if } f(t)>\alpha \\ d\left(p_{1}\right) f(t) & \text { if } f(t) \leq \alpha\end{cases}$

5. Deficiencies are not permissible.

6. The pace of renewal is unlimited, and there is no lead time..

7. The time horizon is infinite .

\section{Theoretical Results and Model Formulation}

At the start of each period, Q units of goods in good condition arrive at the inventory system. The inventory deteriorates $[0, \mathrm{~T}]$ at a steady rate over the inventory period. Furthermore, it loses its freshness over time in response to this physical decay. The price and the freshness of the commodity are expected to decrease by the demand rate. We believe the freshness index falls to a certain level $\alpha$ at time $t=t_{1}, \beta \%$ Discount is provided to increase demand for sale price. Our project aims to investigate the resulting stock management process and determine the most cost-effective solution. $p^{*}$, the best cycle time $T^{*}$, and the best order amount $Q^{*}$. Since the request is deterministic, the significance of theQ if the values of $\mathrm{p}$ and Tare known. "Hence, $\mathrm{p}$, and $\mathrm{T}$ are judgement variables".

\subsection{Model Formulation}

The inventory amount is calculated based on the above conventions. $I(t)$ During the span of time, at time $\mathrm{t}$ $\left[0, t_{1}\right]$ the following differential equation governs the situation:

$\frac{d I_{1}(t)}{d t}=-f(t) d(p)-\theta I_{1}(t), \quad 0 \leq t \leq t_{1} ; 1 \geq f(t) \geq \alpha$

With the boundary condition $I_{1}(0)=Q$

Solving the differential equation in (3), we express the inventory level as follows:

$I_{1}(t)=e^{-\theta t}\left(Q+\frac{d(p)(n \theta+1)}{\theta^{2} n}\right)-\frac{d(p)(n \theta-\theta t+1)}{\theta^{2} n}, \quad 0 \leq t \leq t_{1}$

During the time period $\left[t_{1}, T\right]$ the inventory level $I(t)$ at time tis governed by the following differential equation:

$\frac{d I_{2}(t)}{d t}=-f(t) d\left(p_{1}\right)-\theta I_{2}(t), \quad \mathrm{t}_{1} \leq t \leq T ; \alpha \geq f(t) \geq 0$

With the boundary condition $I_{2}(T)=0$.

Solving the differential equations in (5), we obtain:

$I_{2}(t)=\frac{e^{\theta(T-t)} d\left(p_{1}\right)(-\theta T+n \theta+1)}{\theta^{2} n}-\frac{d\left(p_{1}\right)(-\theta t+n \theta+1)}{\theta^{2} n}, \quad t_{1} \leq t \leq T$

At $t=t_{1} I_{1}\left(t_{1}\right)=I_{2}\left(t_{1}\right)$ therefore

$Q=\frac{1}{\theta^{2} n}\left[e^{\theta T} d\left(p_{1}\right) v-d(p)(n \theta+1)+\left\{d(p)-d\left(p_{1}\right)\right\} w\right]$

where

$v=(1+n \theta-\theta T)$ and $w=\left(1+n \theta-\theta t_{1}\right)$

On the basis of the above, the benefit mechanism during the loop includes: Price of order per cycle:

$O C=K$

The inventory carrying cost per cycle is $H C=\int_{0}^{t_{1}} I_{1}(t) d t+\int_{t_{1}}^{T} I_{2}(t) d t$

$$
\begin{aligned}
H C= & \frac{h}{2 n \theta^{3}}\left[2 e^{\theta T} d\left(p_{1}\right) v+2 e^{\theta t_{1}} w\left(d(p)-d\left(p_{1}\right)\right)-d(p)\left\{\theta^{2} t_{1}\left(2 n-t_{1}\right)+2(n \theta+1)\right\}\right. \\
& \left.+d\left(p_{1}\right) \theta^{2}\left(T-t_{1}\right)\left(T-2 n+t_{1}\right)\right]
\end{aligned}
$$

The purchase cost per cycle is $P C=c Q$

$$
P C=\frac{c}{n \theta^{2}}\left[e^{\theta T} d\left(p_{1}\right) v+e^{\theta t_{1}} w\left\{d(p)-d\left(p_{1}\right)\right\}-d(p)(n \theta+1)\right](11)
$$


The revenue generated by each sales cycle is $S R=p \int_{0}^{t_{1}} f(t) d(p) d t+p_{1} \int_{t_{1}}^{T} f(t) d\left(p_{1}\right) d t$

$S R=\frac{1}{2 n}\left[p\left(2 n-t_{1}\right) d(p) t_{1}-p_{1}\left(T-t_{1}\right)\left(T-2 n+t_{1}\right) d\left(p_{1}\right)\right](12)$

Therefore the profit per cycle is $\pi_{c}=S R-O C-H C-P C$

$$
\begin{aligned}
& \pi_{c}=\frac{1}{2 n}\left[p\left(2 n-t_{1}\right) d(p) t_{1}-p_{1}\left(T-t_{1}\right)\left(T-2 n+t_{1}\right) d\left(p_{1}\right)\right]-K \\
& -\frac{h}{2 n \theta^{3}}\left[2 e^{\theta T} d\left(p_{1}\right) v+2 e^{\theta t_{1}} w\left(d(p)-d\left(p_{1}\right)\right)-d(p)\left\{\theta^{2} t_{1}\left(2 n-t_{1}\right)+2(n \theta+1)\right\}\right. \\
& \left.+d\left(p_{1}\right) \theta^{2}\left(T-t_{1}\right)\left(T-2 n+t_{1}\right)\right]-\frac{c}{n \theta^{2}}\left[e^{\theta T} d\left(p_{1}\right) v+e^{\theta t_{1}} w\left\{d(p)-d\left(p_{1}\right)\right\}-d(p)(n \theta+1)\right]
\end{aligned}
$$

And the benefit per unit time may be as follows:

$$
\begin{aligned}
\pi(p, T) & =\frac{1}{T}\left[\frac{1}{2 n \theta}\left\{t_{1}\left(2 n-t_{1}\right) d(p)(h+\theta p)-\left(T-t_{1}\right)\left(T-2 n+t_{1}\right) d\left(p_{1}\right)\left(h+\theta p_{1}\right)\right\}\right. \\
& \left.-\frac{(h+\theta c)}{n \theta^{3}}\left\{e^{\theta T} v d\left(p_{1}\right)+e^{\theta t_{1}} w\left(d(p)-d\left(p_{1}\right)\right)-d(p)(n \theta+1)\right\}-K\right]
\end{aligned}
$$

Where $\mathrm{v}$ and ware given by equation (8)

\subsection{Solution and Results}

The following is the optimization topic discussed in this article:

$\max _{p, T} \pi(p, T)$

Subject to $c<p, 0<t_{1}<T \leq n$

This topic can be divided into two different optimization problems. The first is a problem of optimization with respect to $\mathrm{T}$, and the second is a problem of optimization with respect top.

3.2.1 Optimization with respect to $\mathrm{T}$

Here we study the function $\pi(p, T)$ for a fixed value ofp.

Proposition 1: If $\left(h+\theta p_{1}\right)>e^{\theta T}(h+\theta c)(1+\theta T-n \theta)$ then

a. There is a one-of-a-kind attribute $T^{*}$ where the benefit function exists $\pi(p, T)$ reaches the maximum potential;

Proof.

b. The answer $T^{*}$ satisfies the second order criterion for a maximal value in (a).

By taking first order derivative of $\pi(p, T)$ in (14) with respect to $\mathrm{T}$ for a fixed $\mathrm{p}$, simplifying and arranging terms, we obtain.

$$
\begin{aligned}
& \frac{d \pi(p, T)}{d T}=-\frac{1}{T^{2}}\left[\frac{1}{2 n \theta}\left\{t_{1}\left(2 n-t_{1}\right)(h+\theta p) d(p)+\left(h+\theta p_{1}\right)\left(T^{2}-2 n t_{1}+t_{1}^{2}\right) d\left(p_{1}\right)\right\}\right. \\
& \left.-\frac{(h+\theta c)}{\theta^{3} n}\left\{e^{\theta T}(1+n \theta-v \theta T) d\left(p_{1}\right)+e^{\theta t_{1}} w\left(d(p)-d\left(p_{1}\right)\right)-d(p)(n \theta+1)\right\}-K\right]
\end{aligned}
$$

The expression of $\frac{d \pi(p, T)}{d T}$ in (16) is a ratio. Therefore $\frac{d \pi(p, T)}{d T}=0$ has a answer $\left(T=T^{*}\right)$ if the numerator is equal to zero at $T=T^{*}$. As a result, think of the numerator of the ratio in (16) as the function. $F(T)$

$$
\begin{aligned}
F(T) & =\frac{1}{2 n \theta}\left\{t_{1}\left(2 n-t_{1}\right)(h+\theta p) d(p)+\left(h+\theta p_{1}\right)\left(T^{2}-2 n t_{1}+t_{1}^{2}\right) d\left(p_{1}\right)\right\}-K \\
& -\frac{(h+\theta c)}{\theta^{3} n}\left\{e^{\theta T}(1+n \theta-v \theta T) d\left(p_{1}\right)+e^{\theta t_{1}} w\left(d(p)-d\left(p_{1}\right)\right)-d(p)(n \theta+1)\right\}
\end{aligned}
$$

By differentiating $F(T)$ with respect to T, simplifying and arranging terms, we obtain: 
$\frac{d F(T)}{d T}=\frac{T\left(\left(h+\theta p_{1}\right)-e^{\theta T}(h+\theta c)(1+\theta T-n \theta)\right) d\left(p_{1}\right)}{n \theta}$

Research Article

From (18) if $\left(h+\theta p_{1}\right)>e^{\theta T}(h+\theta c)(1+\theta T-n \theta)$ then $\frac{d F(T)}{d T}>0$. Thus $F(T)$ With respect to $\mathrm{T}$, is purely increasing.

Furthermore considering (17) we have $F(0)<0$ and $\lim _{T \rightarrow \infty} F(T)=+\infty$

Given the information presented above and the fact that $F(T)$ We should assume that if is continuous, $\left(h+\theta p_{1}\right)>e^{\theta T}(h+\theta c)(1+\theta T-n \theta)$ Then there is a one-of-a-kind attribute of $\mathrm{T}$, say $T^{*}$ such that $F\left(T^{*}\right)=0$. So, if $\left(h+\theta p_{1}\right)>e^{\theta T}(h+\theta c)(1+\theta T-n \theta)$ then $\frac{d \pi(p, T)}{d T}=0$ admits a unique solution $T^{*}$.

Otherwise $F(T) \leq F(n) \leq 0$ and $\frac{d \pi(p, T)}{d T}=-\frac{F(T)}{T^{2}}>0$. In this circumstance $\pi(p, T)$ in accordance with is growing $\mathrm{T}$ on $[0, n]$, It reaches its highest point at $T=n$.

Now, we investigate what constitutes a sufficient condition for $T^{*}$ to be the pinnacle of one's abilities by taking the derivative of the second derivative of $\pi(p, T)$ in (14) with respect to T, We obtain terms by simplifying and organizing them.:

$$
\begin{aligned}
& \frac{d^{2} \pi(p, T)}{d T^{2}}=\frac{2}{T^{3}}\left[\frac{1}{2 n \theta}\left\{t_{1}\left(2 n-t_{1}\right)(h+\theta p) d(p)+\left(h+\theta p_{1}\right)\left(T^{2}-2 n t_{1}+t_{1}^{2}\right) d\left(p_{1}\right)\right\}\right. \\
& \left.-\frac{(h+\theta c)}{\theta^{3} n}\left\{e^{\theta T}(1+n \theta-v \theta T) d\left(p_{1}\right)+e^{\theta t_{1}} w\left(d(p)-d\left(p_{1}\right)\right)-d(p)(n \theta+1)\right\}-K\right] \\
& -\frac{d\left(p_{1}\right)}{n \theta T}\left[\left(h+\theta p_{1}\right)-(h+\theta c) e^{\theta T}(1+\theta T-n \theta)\right]
\end{aligned}
$$

At $T=T^{*}$, we have

$$
\begin{aligned}
& \frac{d^{2} \pi\left(p, T^{*}\right)}{d T^{2}}=\frac{2}{T^{* 3}}\left[\frac{1}{2 n \theta}\left\{t_{1}\left(2 n-t_{1}\right)(h+\theta p) d(p)+\left(h+\theta p_{1}\right)\left(T^{* 2}-2 n t_{1}+t_{1}^{2}\right) d\left(p_{1}\right)\right\}\right. \\
& \left.-\frac{(h+\theta c)}{\theta^{3} n}\left\{e^{\theta T}\left(1+n \theta-v \theta T^{*}\right) d\left(p_{1}\right)+e^{\theta t_{1}} w\left(d(p)-d\left(p_{1}\right)\right)-d(p)(n \theta+1)\right\}-K\right] \\
& -\frac{d\left(p_{1}\right)}{n \theta T^{*}}\left[\left(h+\theta p_{1}\right)-(h+\theta c) e^{\theta T^{*}}\left(1+\theta T^{*}-n \theta\right)\right]
\end{aligned}
$$

Taking into account the requisite conditions for a successful outcome

$$
\begin{aligned}
& \left(\text { i.e. } \frac{d \pi\left(p, T^{*}\right)}{d T}=0\right) \text { and replacing } \mathrm{T} \text { by } \mathrm{T}^{*} \text { in (17), we obtain : } \\
& \frac{1}{2 n \theta}\left\{t_{1}\left(2 n-t_{1}\right)(h+\theta p) d(p)+\left(h+\theta p_{1}\right)\left(T^{* 2}-2 n t_{1}+t_{1}^{2}\right)\right\} d\left(p_{1}\right) \\
& =\frac{(h+\theta c)}{\theta^{3} n}\left\{e^{\theta T}\left(1+n \theta-v \theta T^{*}\right) d\left(p_{1}\right)+e^{\theta t_{1}} w\left(d(p)-d\left(p_{1}\right)\right)-d(p)(n \theta+1)\right\}-K
\end{aligned}
$$

Plugging (21) into (20), we obtain:

$$
\frac{d^{2} \pi\left(p, T^{*}\right)}{d T^{2}}=-\frac{d\left(p_{1}\right)}{n \theta T^{*}}\left[\left(h+\theta p_{1}\right)-(h+\theta c) e^{\theta T^{*}}\left(1+\theta T^{*}-n \theta\right)\right]
$$


As we $\quad \operatorname{assume}\left(h+\theta p_{1}\right)>e^{\theta T}(h+\theta c)(1+\theta T-n \theta), \quad$ we Research Article $\left(h+\theta p_{1}\right)-e^{\theta T}(h+\theta c)(1+\theta T-n \theta)>0$. Then we conclude that $\frac{d^{2} \pi(p, T)}{d T^{2}}<0$, and the best revenue $\pi(p, T)$ at $T=T^{*}$ is a maximum.

\subsection{2 $p$-related optimization}

In this section, we'll look at situations where the best price is available and is one-of-a-kind. Regardless of the circumstances $T^{*}$, the first and most important requirement for $\pi\left(p, T^{*}\right)$ to be maximize is $\frac{\partial \pi\left(p, T^{*}\right)}{\partial p}=0$, that is;

$$
\begin{aligned}
& \frac{\partial \pi\left(p, T^{*}\right)}{\partial p}=\frac{1}{T^{*}}\left[-b\left\{\frac{t_{1}\left(2 n-t_{1}\right)(h+\theta p)}{2 n \theta}-\frac{(h+\theta c)\left(e^{\theta t_{1}} w-n \theta-1\right)}{n \theta^{3}}\right\}\right. \\
& +\frac{d(p) t_{1}\left(2 n-t_{1}\right)}{2 n}-b \beta\left\{\left(T^{*}-t_{1}\right)\left(T^{*}-2 n+t_{1}\right)\left(h+\theta p_{1}\right)+\frac{(h+\theta c)\left(e^{\theta T^{*}} v-e^{\theta t_{1}} w\right)}{n \theta^{3}}\right\}(23) \\
& \left.+d\left(p_{1}\right)\left(T^{*}-t_{1}\right)\left(T^{*}-2 n+t_{1}\right) \beta \theta\right]=0
\end{aligned}
$$

Equation (23) has a solution, which is obvious. Furthermore, the derivation of the second order of $\pi\left(p, T^{*}\right)$ with respect to $\mathrm{p}$ is:

$$
\frac{\partial^{2} \pi\left(p, T^{*}\right)}{\partial p^{2}}=-\frac{1}{T^{*}}\left[\frac{b t_{1}\left(2 n-t_{1}\right)}{n}+2 b \beta^{2} \theta\left(T^{*}-t_{1}\right)\left\{\left(n-T^{*}\right)+\left(n-t_{1}\right)\right\}\right]<0 \text { (24) }
$$

Consequently $\pi\left(p, T^{*}\right)$ is a convex function of $\mathrm{p}$ for a given $T^{*}$, hence a value of $\mathrm{p}$ that obtain from (23) is unique. So it is proved that the unique value of $\mathrm{p}$ is obtained from (23) maximizes $\pi\left(p, T^{*}\right)$

\subsubsection{An Algorithm for Determining the Best Solution $\left(p^{*}, T^{*}\right)$}

We show how to determine the best solution using a simple algorithm. $\left(p^{*}, \mathrm{~T}^{*}\right)$ in order to solve the inventory issue

Step 1. Start with $j=0$ and an initial trial value of the price $p_{j}=p_{1}$.

Step 2. Find the maximum values of $\pi\left(p_{j}, T\right)$ in (14) by calculus method.

Step 3. Use the result in step 2 to determine the optimal price $p_{j+1}$ by (23).

Step 4. If the difference between $p_{j}$ and $p_{j+1}$ is small enough, set $p^{*}=p_{j+1}$, and $\left(p^{*}, T^{*}\right)$ is the optimal solution, and stop. If not, set $j=j+1$ and go back to step 2 .

\section{Sensitivity Analysis and Numerical Examples}

This section includes numerical examples that back up the empirical findings drawn in the previous section. Let us consider $d(p)=a-b p$, and $p_{1}=(1-\beta) p$.

Example 1 For the inventory system, consider the following details: $\mathrm{K}=\$ 500$ /order, $\mathrm{c}=\$ 10 / \mathrm{unit}, \mathrm{h}=\$ 1 / \mathrm{unit}$ time $\theta=0.1, \mathrm{a}=450, \mathrm{~b}=5.4, \beta=15 \%, \alpha=0.7, \mathrm{n}=0.5$ years.

The following optimal prices, with this model parameter value and the implementation of the above algorithm, the inventory cycle, the quantity of the order, and the corresponding optimal profit are obtained.

$: p^{*}=48.99, T^{*}=0.2598, Q^{*}=38.70, \pi\left(p^{*}, T^{*}\right)=3365.20$

We resolve the model with different values for each parameter in order to do a sensitivity analysis while maintaining the other parameter constant. Table 1 displays our model's optimal solution for various freshness index values $\alpha$ of the commodity In addition to the values of the model's other parameters, which are mentioned above. 


\begin{tabular}{ccccc}
\multicolumn{5}{c}{ Table 1. Sensitivity of the best solution in terms of $\alpha$} \\
\hline$\alpha$ & $T^{*}$ & $p^{*}$ & $Q^{*}$ & Profit \\
\hline 0.85 & 0.2634 & 51.44 & 39.08 & 3358.88 \\
0.8 & 0.2626 & 50.53 & 39.02 & 3356.27 \\
0.75 & 0.2614 & 49.72 & 38.89 & 3358.79 \\
0.7 & 0.2598 & 48.99 & 38.70 & 3365.20 \\
0.65 & 0.2580 & 48.35 & 38.47 & 3374.49 \\
0.6 & 0.2561 & 47.78 & 38.21 & 3385.84 \\
0.55 & 0.2542 & 47.27 & 37.94 & 3398.51 \\
\hline
\end{tabular}

If the product's refreshes reduces the overall period time, the optimum sale price and the optimum order amount decreases and benefit decreases first and subsequently increases as product freshness decreases.

Table 2 presents the optimum solution for the various sale price percentage values in our model, while the other model parameter remains unchanged.

Table 2. Sensitivity of the best solution in terms of $\beta$

\begin{tabular}{ccccc}
\hline$\beta$ in $\%$ & $T^{*}$ & $p^{*}$ & $Q^{*}$ & Profit \\
\hline 05 & 0.2612 & 47.56 & 38.57 & 3409.89 \\
10 & 0.2607 & 48.30 & 38.62 & 3393.45 \\
15 & 0.2598 & 48.99 & 38.70 & 3365.20 \\
20 & 0.2582 & 49.62 & 38.77 & 3324.19 \\
25 & 0.2556 & 50.15 & 38.82 & 3269.63 \\
30 & 0.2516 & 50.57 & 38.77 & 3201.01 \\
35 & 0.2452 & 50.80 & 38.51 & 3118.48 \\
40 & 0.2351 & 50.77 & 37.80 & 3023.51 \\
45 & 0.2179 & 50.29 & 36.05 & 2921.02 \\
50 & 0.1816 & 48.60 & 30.92 & 2828.85 \\
\hline
\end{tabular}

It is visible from table 2 that higher the percentage discount offered on selling price results in short cycle length, lower the profit, but optimal selling price and order quantity first increases and then decreases.

For the various values of the request parameters $a$ and $b$ the optimum solution of our model is shown in table 3 , while other model parameters remain unchanged respectively.

Table 3. With respect to a and b, the optimal solution's sensitivity

\begin{tabular}{|c|c|c|c|c|c|c|}
\hline & Parameter & $\begin{array}{c}\text { Values of the } \\
\text { parameter }\end{array}$ & $T^{*}$ & $p^{*}$ & $Q^{*}$ & Profit \\
\hline & \multirow{7}{*}{$a$} & 375 & 0.3235 & 42.25 & 35.78 & 1614.14 \\
\hline & & 400 & 0.2993 & 44.53 & 36.92 & 2139.38 \\
\hline & & 425 & 0.2782 & 46.77 & 37.89 & 2723.03 \\
\hline & & 450 & 0.2598 & 48.99 & 38.70 & 3365.20 \\
\hline & & 475 & 0.2435 & 51.19 & 39.37 & 4066.04 \\
\hline & & 500 & 0.2289 & 53.37 & 39.94 & 4825.71 \\
\hline & & 525 & 0.2158 & 55.52 & 40.40 & 5644.41 \\
\hline \multirow{6}{*}{$b$} & 4.2 & 0.2204 & 60.75 & 35.54 & 5370.58 & \\
\hline & 4.6 & 0.2338 & 56.17 & 36.72 & 4572.16 & \\
\hline & 5.0 & 0.2469 & 52.31 & 37.77 & 3914.51 & \\
\hline & 5.4 & 0.2598 & 48.99 & 38.70 & 3365.20 & \\
\hline & 5.8 & 0.2726 & 46.13 & 39.52 & 2900.98 & \\
\hline & 6.2 & 0.2853 & 43.62 & 40.24 & 2504.72 & \\
\hline
\end{tabular}


From table 3 one can observed that higher values of a, results in higher values of optimal selling price, order quantity and profit but short cycle length. Higher value of $b$ results in higher value of order quantity, longer the cycle length but lower the optimal selling price and profit.

\section{Conclusions and Research Directions in the Future}

This paper created a model for the inventory of perishable products that is based on the sales price and freshness index. When the object is saved, the lack of freshness is taken into account. The percentage discount on the sales price will be calculated by using freshness. In terms of cycle time, the benefit function appears concave. For the presence of the specific optimal solution, conditions are listed. Numerical examples and sensitivity analysis were presented to the key parameters of the model.

The proposed model can be generalized by allowing shortages. In addition, a decision variable on the percentage reduction in selling prices will generalize the model.

\section{Conflict of Interest}

The authors confirm that there is no conflict of interest to declare for this publication.

\section{References}

1. Abad, P.L., (2003). Optimal pricing and lot-sizing under conditions of perishability, finite production and

2. partial backordering and lost sale. European Journal of Operational Research, 144(3), 677-685.

3. Agi, M.A., \&Soni, H.N., (2019). Joint pricing and inventory decisions for perishable products with age-

4. stock-, and price-dependent demand rate. Journal of the Operational Research Society, 71(1), 85-99.

5. Bai, R. \& Kendall G., (2008). A model for fresh product shelf space allocation and inventory management

6. with freshness condition dependent demand. Informs Journal on Computing, 20(1) 78-85.

7. Bakker, M., Riezebos, J., \& Teunter, R.H., (2012). Review of inventory systems with deterioration since

8. 2001.European Journal of Operational Research, 221(2), 275-284.

9. Banerjee, S. \& Agrawal, S., (2017). Inventory model for deteriorating items with freshness and price

10. dependent demand: Optimal discounting and ordering policies. Applied Mathematical Modelling, 52,

11. 53-64.

12. Bhaula, B., Dash, J. K. \& Kumar, M. R., (2019). An optimal inventory model for perishable items under

13. successive price discounts with permissible delay in payments. Operational Research Society of India,

14. 56, 261-281.

15. Chang, H.J., Teng, J.T., Ouyang, L.Y. \& Dye, C.Y., (2006). Retailer's optimal pricing and lot- sizing policies

16. for deteriorating items with partial backlogging.European Journal of Operational Research,168(1),

17. $51-64$

18. Chen, S. C., Min, J., Teng, J. T., \& Li, F., (2016). Inventory and shelf-space optimization for fresh produce

19. with expiration date under freshness and stock dependent demand rate. Journal of the Operational

20. Research Society, 67(6), 884-896.

21. Debata, S., \& Acharya, M., (2017). An inventory control for non-instantaneous deteriorating items with non

22. zero lead time and partial backlogging under joint price and time dependent demand.International

23. Journal of Applied and Computational Mathematics, 3(2), 1381-1393.

24. Demirag, O. C., Kumar, S. \& Rao, K.S.M., (2017). A note on inventory policies for products with residual

25. life-dependent demand.Applied Mathematical Modelling, 43, 647-658.

26. Dobson, G., Pinker, E. J., \& Yildiz, O, (2017). An EOQ model for perishable goods with age-dependent

27. demand rate.European Journal of Operational Research, 257(1), 84-88.

28. Dye, C.Y., (2007). Joint pricing and ordering policy for deteriorating inventory with partial backlogging.

29. Omega, 35(2), 184-189.

30. Fujiwara, O., Perera, \& U. L. J. S. R., (1993). EOQ models for continuously deteriorating productsusing

31. linear and exponential penalty costs.European Journal of Operational Research, 70(1) 104-114.

32. Farughi, H., Khanlarzade, N. \& Yegane, B. Y., (2014). Pricing and inventory control policy for non

33. instantaneous deteriorating items with time and price dependent demand and partial backlogging.

34. Decision Science Letters, 3(3), 325-334. 
35. Feng, L. Y. L., Chan, L. E., \& Cardenas-Barron, (2017). Pricing and lot-sizing polices for perishable goods

36. when the demand depends on selling price, displayed stocks, and expiration date. International Journal

37. of Production Economics, 185,11-20.

38. Ghoreishi, M., Mirzazadeh, A. \& Weber, G.W., (2014). Optimal pricing and ordering policy for non

39. instantaneous deteriorating items under inflation and customer returns. Optimization 63 (12), 1785-

40. 1804

41. Goyal, S. K., \& Giri, B. C., (2001). Recent Trends in Modeling of Deteriorating Inventory. European

42. Journal of Operational Research, 134(1) 1-16.

43. Herbon, A., (2014). Dynamic pricing vs. acquiring information on consumers' heterogeneous sensitivity to

44. product freshness. International Journal of Production Research, 52(3), 918-933.

45. Hsieh, T.P., \& Dye, C.Y. (2010). Pricing and lot-sizing policies for deteriorating items with partial

46. backlogging under inflation. Expert Systems with Applications, 37(10), 7234-7242.

47. Janssen, L., Claus, T., \& Sauer, J., (2016). Literature review of deteriorating inventory models by key

48. topics from 2012 to 2015. International Journal of Production Economics, 182, 86-112.

49. Kamaruzaman N.A., \& Omar, M., (2020). Inventory model for a fresh product when demand depends on

50. freshness, price, inventory level and expiration date under markdown policy. Journal of Intelligent and

51. Fuzzy Systems, 1-9.

52. Li, R. \& Teng, J. T., (2018).Pricing and lot-sizing decisions for perishable goods when demand depends on

53. selling price, reference price, product freshness, and displayed stocks. European Journal of Operational

54. Research, 270(3) $1099-1108$.

55. Liu, G., Zhang, J. \& Tang, W., (2015). Joint dynamic pricing and investment strategy for perishable foods

56. with price-quality dependent demand. Annals of Operations Research, 226(1), 397-416.

57. Maihami, R., \& Kamalabadi, I. N., (2012). Joint pricing and inventory control for non- instantaneous

58. deteriorating items with partial backlogging and time and price dependent demand. International

59. Journal of Production Economics, 136(1), 116-122.

60. Mukhopadyay, S, Mukherjee, R.N. \& Chaudhuri, K.S., (2004). Joint pricing and ordering policy for a

61. deteriorating inventory. Computers \& Industrial Engineering, 47(4), 339-349.

62. Nahmias, S., (1982). Perishable Inventory Theory: A Review. Operations Research, 30(4), 680-708.

63. Qin, Y., Wang, J. \& Wei C., (2014). Joint pricing and inventory control for fresh produce and foods with

64. quality and physical quantity deteriorating simultaneously. Int. J. Production Economics, 152, 42-48.

65. Rabbani, M., Zia, N.P. \& Rafiei, H., (2016). Joint optimal dynamic pricing and replenishment policies for

66. items with simultaneous quality and physical quantity deterioration. Applied Mathematics and

67. Computation 287-288, 149-160.

68. Raafat, F., (1991). Survey of literature on continuously deteriorating inventory models. The Journal of the

69. Operational Research Society, 42, 27-37.

70. Sana, S., (2010). Optimal selling price and lot size with time varying deterioration and partial backlogging.

71. Applied Mathematics and Computation, 217(1), 185-194.

72. Sana, S., (2011). Price-sensitive demand for perishable items-an EOQ model. Applied Mathematics and

73. Computation, 217(13), 6248-6259.

74. Sarker, B. R., Mukherjee, S. \& Balan, C. V., (1997). An Order-level Lot Size Inventory Model with Inventory

75. -level Dependent Demand and Deterioration. International Journal of Production Economics, 48,227-

76. 236.

77. Tsiros, M., \& Heilman, C. M., (2005). The effect of expiration dates and perceived risk on purchasing

78. behavior in grocery store perishable categories. Journal of Marketing, 69(2), 114-129.

79. Wang, X., \& Li, D., (2012). A dynamic product quality evaluation based pricing model for perishable food

80. supply chains. Omega, 40(6), 906-917.

81. Wee, H.M., (1997). A replenishment policy for items with a price-dependent demand and a varying rate of

82. deterioration. Production Planning and Control, 8(5), 494-499.

83. Wu, J., Chang, C. T., Cheng, M. C., Teng, J. T., \& Al-Khateeb, F. B., (2016). Inventory management for

84. fresh produce when the time varying demand depends on product freshness, stock level and expiration

85. date", International Journal of Systems Science: Operations \& Logistics, 3, 138-147. 
86. Zhou, W., \& Piramuthu, S., (2013). RFID and perishable inventory management with shelf-space and 87. freshness dependent demand, International Journal of Production Economics, 144(2), 635-640. 